\title{
Time Variations Analysis of the Geomagnetic Field in the Municipality of Macaé, Brazil
}

\author{
Laisa Prata Moreira Fernandes', João Victor Jobim de Souza e Silva1, Iago Reis Homsi', \\ Paula de Carvalho Garcia1, Gabriel Teixeira de Oliveira Barroso1, Tainá Rebelo e Ribeiro1, \\ Gabriel Gomes Dias de Oliveira1, Vânia Regina de Oliveira Branco', \\ Hans Schmidt Santos ${ }^{2}$
}

${ }^{1}$ Instituto Nossa Senhora da Glória (INSG), Macaé, Brazil

${ }^{2}$ Faculdade Salesiana Maria Auxiliadora (FSMA), Macaé, Brazil

Email: hans.schmidt@live.com

How to cite this paper: Fernandes, L.P.M., de Souza e Silva, J.V.J., Homsi, I.R., de Carvalho Garcia, P., de Oliveira Barroso, G.T., e Ribeiro, T.R., de Oliveira, G.G.D., de Oliveira Branco, V.R. and Santos, H.S. (2020) Time Variations Analysis of the Geomagnetic Field in the Municipality of Macaé, Brazil. Open Access Library Journal, 7: e6646. https://doi.org/10.4236/oalib.1106646

Received: July 23, 2020

Accepted: August 21, 2020

Published: August 24, 2020

Copyright $\odot 2020$ by author(s) and Open Access Library Inc.

This work is licensed under the Creative Commons Attribution International License (CC BY 4.0).

http://creativecommons.org/licenses/by/4.0/

\begin{abstract}
This paper presents the analysis of temporal variations of the geomagnetic field in the municipality of Macaé, Brazil. Current and historical magnetic field from the IGRF (International Geomagnetic Reference Field) and Gufm1 models were used to construct two-dimensional maps from 1590 to 2019. Analysis of the maps revealed that there was a large decrease in total magnetic field magnitude from around 48,000 nT in 1590 to $23,000 \mathrm{nT}$ in 2019, i.e., a decrease of more than $50 \%$. This decrease was interpreted as a direct influence of the east to west displacement of the South Atlantic Magnetic Anomaly (SAMA) in the last centuries.
\end{abstract}

\section{Subject Areas}

Environmental Sciences, Geology, Geomorphology, Geophysics

\section{Keywords}

Geomagnetism, IGRF, Gufm1, South Atlantic Magnetic Anomaly

\section{Introduction}

The Earth's magnetic field varies in time and space. For many applications, it can be approximated by a dipolar field located in the center of the Earth, with an inclination of approximately $11.5^{\circ}$ between the dipole axis and the rotation axis of the Earth [1].

The Earth's magnetic field can be perceived in the handling of a compass, as it will align with the magnetic poles. Another known effect of the Geomagnetic 
Field is its great influence on the movement of free ions and electrons that are present in the Earth's ionosphere. Particles from the Solar Wind have their trajectory altered due to the Earth's magnetic field, thus preventing the direct incidence of such particles. It can also be noticed the alteration in the propagation of electromagnetic waves in the ionosphere caused by the Earth's magnetic field [2].

Perceptible variations of the geomagnetic field over time can occur in fractions of seconds or thousands of years, and it can be periodic or completely random. These temporal variations can be long and short. The best known of the long-term variations is the secular variation that presents changes in the order of years, having its origin in the outer core of the Earth [1].

Historical magnetic data obtained by navigators from 1550 onwards has been used in several surveys of geomagnetic field. Taking Barraclough (1974) [3] as an example, developed models from 1600 to 1910 . With the expansion of magnetic data collection in the last century, other historical data models were also built, such as Jackson's Gufm1 (2000) [4] and also more modern and precise models such as the IGRF (International Geomagnetic Reference Field) by Alken et al. (2020) [5].

The South Atlantic Magnetic Anomaly (SAMA) is a small region of the Earth that presents the magnetic field with a very low intensity compared to the other regions of the planet. This anomaly is located in the South Atlantic region, having been discovered only in the 1950. In the central part of the anomaly, the intensity of the magnetic field is around 23,000 $\mathrm{nT}$, which can be considered a global minimum. This anomaly is not static, and it is currently moving from east to west [2].

According to Hartmann (2010) [6], analysis of field models for the period 1590-2005 AD indicates that the SAMA has been present on Earth for at least 500 years. It is believed that the origin of the anomaly may be related to instability effects at the mantle-core interface, which are the main sources generating the non-dipolar field.

In this context, it is studied the effect of the SAMA in the municipality of Macaé, Brazil, located on the coast of the Atlantic Ocean. The region has its geomagnetic field greatly influenced by this anomaly as noticed in the models of the last 500 years. Thus, this paper intends to analyze the SAMA effect in the municipality of Macaé, Brazil with data from the IGRF and Gufm1 models of the last centuries. Thus, it is intended to verify its effects by assessing the decrease in the intensity of the total magnetic field and the change in the magnetic declination values.

Thus, section II will describe the study region; section III will describe the Earth's magnetic field, the South Atlantic Magnetic Anomaly and the models used in this work: IGRF and Gufm1; section IV will present the results and the discussion of the maps obtained by processing; and, finally, section $\mathrm{V}$ presents the conclusions. 


\section{Macaé County}

The Macaé County is located in the north of the state of Rio de Janeiro, Brazil. It's bathed by the Atlantic Ocean in easterly direction, being its localization by the red mark in Figure 1 [7].

The county origin was marked by the colonization of the Jesuits (religious order that preached the Catholicism), who built a farm, a chapel and a school. In 1795, the Jesuits were expelled and a village started. Due to its growth, it was placed as "São João de Macaé" village and later, in 1847, it was considered officially a city. The gold period, the coffe growing, the sugar cane exploration and others periods preceded 1974, when oil was discovered in the city. It is then known as "Brazilian Oil Capital" [8].

With this in mind, workers from different parts of Brazil and the World move to the region due to work. According to the 2010 Brazilian Census, the population grows about $4.5 \%$ per year, being the 13th most populous city in the state of Rio de Janeiro. Macaé has a demographic density of 170 inhabitants per square kilometer and occupies about 12.5\% of the Northern Fluminense Region [9].

\section{Theoretical Foundations}

\subsection{Terrestrial Magnetism}

The magnetism concept originated in the 3rd century BC, through Asian peoples who noted its influence through the use of the compass. In the 16th century, Gilbert stated that it is originated in the deepest layer of the Earth and it would be like a giant magnet. Thus, the Earth would produce the magnetic field itself. In the seventeenth century, René Descartes portrays the magnetic field through "Field Lines" that form a closed cycle, because these "lines" entered the North Pole and left through the South Pole. Together with the in-depth studies of Carl Friedrich Gauss and his improvement in the calculation of the total intensity, it was possible to confirm the origin of the magnetic field from the interior of the

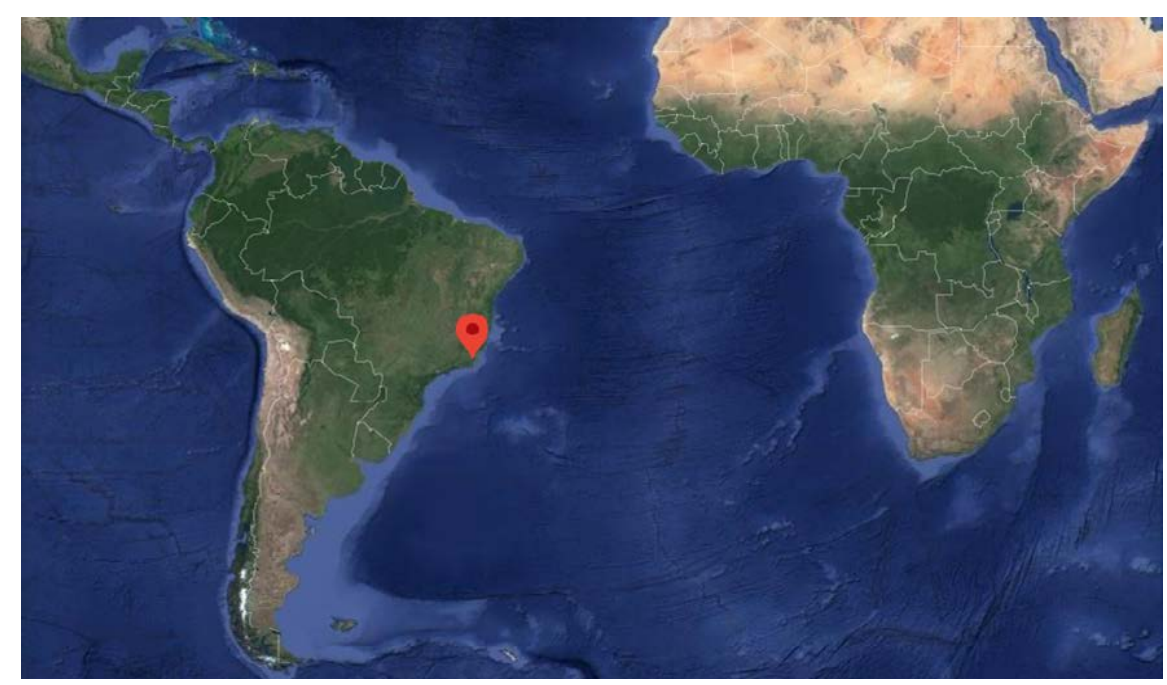

Figure 1. Macaé Municipality Location [7]. 
Earth. Thus, Gauss established a technique of analysis based on a spherical harmonic model to name magnetic fields of different origins, are these, the external, internal and crustal fields [10].

Furthermore, it was determined that the magnetic field undergoes variations in amplitude and direction over the years, so sudden changes are possible. These variations originate from three important points: the main field (where there is movement of substance in the Earth's core), the field of the Earth's crust (volcanic activities generate a new crust from solidification of magma, causing it to orient to the magnetic north), the external field (interactions with the solar wind). Secular variation is the name given to the phenomenon of slow magnetic variation over time [11].

The Terrestrial Magnetic Field is composed of vector and angular quantities according to Figure 2:

Where, vector quantities: component X; component Y; component Z, intensities $\mathrm{H}$ and $\mathrm{F}$, and angular magnitudes: inclination angle (I) and declination angle (D).

Declination (D), Inclination (I), Horizontal Field (H) and Total Intensity (F) are obtained by the equations:

$$
\begin{aligned}
& D=\operatorname{tg}^{-1}\left(\frac{Y}{X}\right) \\
& I=\operatorname{tg}^{-1}\left(\frac{Z}{H}\right) \\
& H=\sqrt{X^{2}+Y^{2}} \\
& F=\sqrt{H^{2}+Z^{2}}
\end{aligned}
$$

The Geographic North Pole is the location of the meeting point between the planet Earth with its axis of rotation, however, the magnetic pole is a variable point, result of fluids and movements of the Earth's core, which points to the Magnetic South Pole (which is close to the Geographic North Pole). The differences between the magnetic poles and the geographic poles show that the geomagnetic field is not constituted of a perfect geocentric dipole [1].

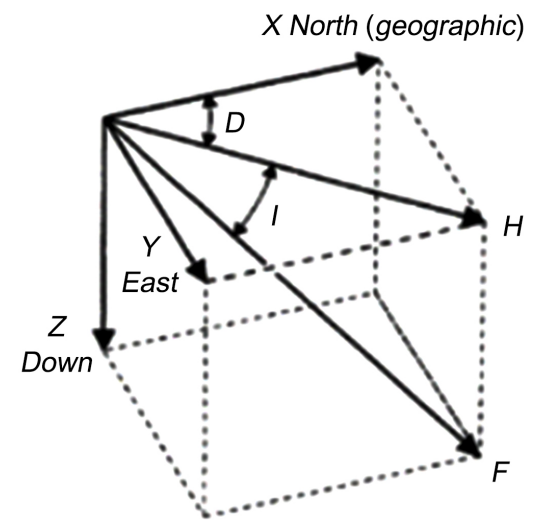

Figure 2. Representation of the magnetic field and its projected components [1]. 
The Magnetic South Pole has a slope of -90 degrees. The so-called "Magnetic Equator" is characterized by the line of zero inclination near the equator. The angles located between the geographical north and the magnetic north is titrated as magnetic declination, and it assumes a positive declination in the east and negative in the west [1].

Given that the intensity and components of the magnetic field vary with space and time, there are regions on the planet that have a low magnetic field, that are, areas vulnerable to foreign particles as well as radiation. The South Atlantic Magnetic Anomaly (SAMA) is an example of this area of abnormality. There is speculation that this magnetic fragility will extend throughout the Southern hemisphere until around 2240 [12].

\subsection{South Atlantic Magnetic Anomaly}

It is known that the magnetic field is stronger near the poles. Otherwise, there are areas on Earth with a lower intensity of magnetic field and that are constantly weakening. These areas have not been stationary over the years. There is, therefore, a scientific nomination for this phenomenon, South Atlantic Magnetic Anomaly, which has an extensive area of about 4.8 million square kilometers and is currently located in the South Atlantic and southern of South America [10].

The nomenclature "South Atlantic Magnetic Anomaly" was given at the time when measurements of the Earth's magnetic field began to be taken (from 1850), when most of its area was located over the South Atlantic Ocean, however currently, SAMA comprises the South American continental region as shown in Figure 3 [1]

Currently, SAMA has an elongated shape extending from South America to Africa, with the region of least intensity of the magnetic field located in the interior of Paraguay [10].

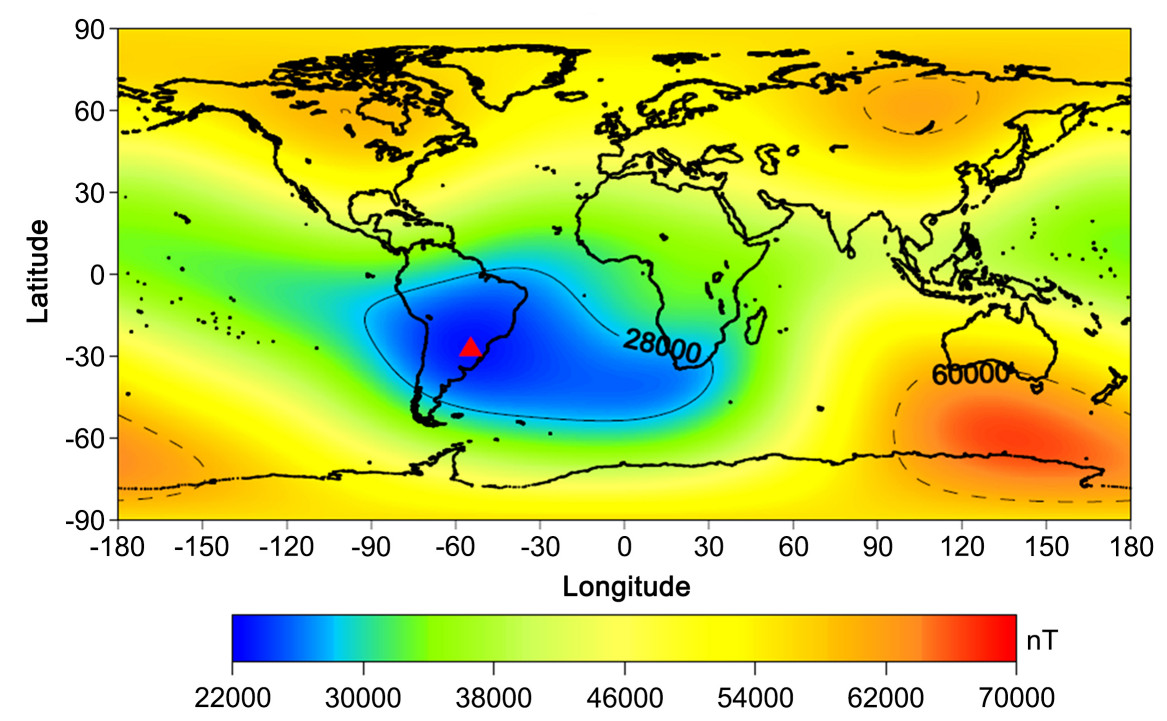

Figure 3. South Atlantic Magnetic Anomaly (in blue) in the year 2000 [10]. 
According to Moro et al. (2007) [2], the anomaly is characterized by having a low intensity of the Total Magnetic Field, with around 23,000 nT in its central part. However, the anomaly varies according to time, as it moves little by little over the Earth's surface.

The origin of the anomaly may be linked to asymmetric distributions of electrical currents within the planet. In this case, a magnetic field would be generated in opposite to the Earth's main field, and consequently the geomagnetic field would be weakened in this region [2].

\subsection{IGRF Model}

The IGRF (International Geomagnetic Reference Field) is a mathematical model based on the expansion in spherical harmonics from the geomagnetic field. The model is proven by international collaboration through cooperation of various institutes responsible for collecting and publishing magnetic field data [13].

The IGRF is a spherical model for the Geomagnetic Field whose sources are in the Earth's core. The IGRF came after discussions by the World Magnetic Survey (WMS) on a set of surveys on the Earth's Magnetic Field, in the seas, skies and other media, between the years 1957 and 1969. However, it has been updated every five years, according to the International Association of Geomagnetism and Aeronomy (IAGA) [14].

According to Alken et al. (2020) [5], IAGA launched the 13th Generation of IGRF in December, 2019. The main field model was finalized by IAGA task force, being the product of a collaborative effort between magnetic field modelers and the institutes involved in the collection and dissemination of satellite magnetic field data, besides observatories around the world.

According to Thébault et al. (2015) [15], the IGRF is a series of mathematical models of the internal geomagnetic field $\vec{B}(r, \theta, \varphi, t)$ and its rate of change (secular variation). On and above the Earth's surface, the magnetic field $\vec{B}$ is defined in terms of a magnetic scalar potential $V$ by $\vec{B}=-\nabla V$ and where in spherical polar coordinates $V$ is approximated by the finite series

$$
\begin{aligned}
V(r, \theta, \varphi, t)= & \alpha \sum_{n=1}^{N} \sum_{m=1}^{n}\left(\frac{a}{r}\right)^{n+1} \\
& \times\left[g_{n}^{m}(t) \cos (m \varphi)+H_{n}^{m}(t) \sin (m \varphi) P_{n}^{m}(\cos \theta)\right]
\end{aligned}
$$

- $r$ (radial distance from the center of the Earth)

- $a=6371.2 \mathrm{~km}$ (Earth's mean reference spherical radius)

- $\theta$ (geocentric co-latitude, and $\varphi$ denoting east longitude)

- $P_{n}^{m}(\cos \theta)$ (Schmidt quasi-normalized associated Legendre functions of degree $n$ and order $m$ )

- $g_{n}^{m}, H_{n}^{m}$ (Gauss coefficients functions of time)

\subsection{Gufm1 Model}

According to Jackson et al. (2000) [4], the Gufm1 model is based on a massive compilation of historical observations of the magnetic field at the core-mantle 
limit of the 1590-1990 interval. For the period prior to 1800 , more than 83,000 individual observations of magnetic declination were recorded in more than 64,000 locations; more than 8000 new observations are only in the 17th century (Figure 4):

According to Jackson et al. (2000) [4] and Jonkers et al. (2003) [16], direct observations of the geomagnetic field with the extensive geographical coverage necessary for the modeling of the Earth's surface have existed since the 16th century through maritime observations, observatory measurements (after 1830), magnetic research (18th, 19th and 20th centuries) and satellite magnetometer data (POGO in the 1960s and MAGSAT in the 1980s).

According to Jonkers et al. (2003) [16], the magnetic field outside the nucleus can be expressed as the gradient of a scalar potential $\mathrm{V}$ that satisfies the Laplace equation and is also a function of time:

$$
B=-\nabla V, \text { where } \nabla^{2} V=0
$$

where it was also assumed that there are no field sources in infinity. By choosing a system of spherical polar coordinates $(r, \theta, \varphi)$, the method of variable separation is used to find the solution to the Laplace equation subject to these boundary conditions in the form of a harmonic expansion:

$$
V(t)=a \sum_{l=1}^{\infty} \sum_{m=0}^{l}\left(\frac{a}{r}\right)^{l+1}\left\{g_{l}^{m}(t) \cos (m \varphi)+h_{l}^{m}(t) \sin (m \varphi)\right\} P_{l}^{m}(\cos \theta)
$$

where only the solutions corresponding to the internal field sources (found in the modeling as the dominant terms) were maintained, $a=6371.2 \mathrm{~km}$ is the mean radius of the Earth and $P_{l}^{m}$ are the associated Legendre functions of Schmidt with degree " $P$ " order " $m$ " with normalization. $g_{l}^{m}(t)$ and $h_{l}^{m}(t)$ are the fourth-order B-Spline basis of the Gauss coefficients.

\section{Processing and Results}

Through the magnetic field data, historical data from the IGRF-12 and Gufm1 models were processed. The data were collected in a quadrant with a variation of

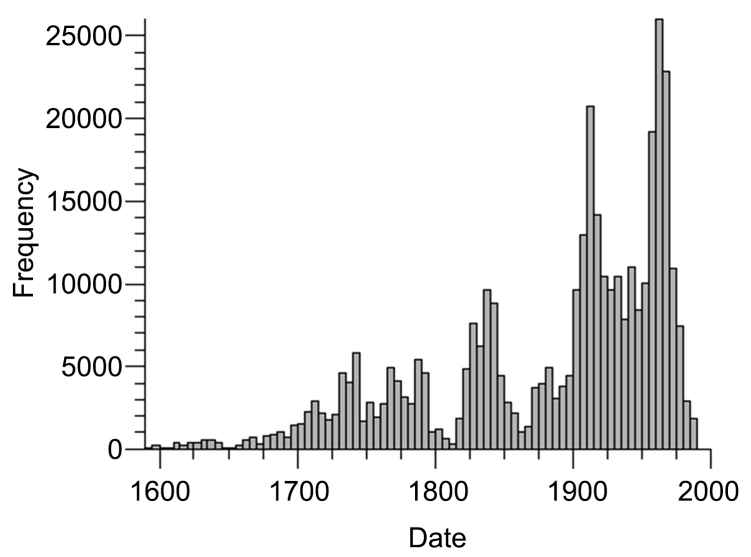

Figure 4. Temporal distribution of measurements used in Gufm 1 model [4]. 
longitude from $45 \mathrm{~W}$ to $40 \mathrm{~W}$ and variation of latitude from $24 \mathrm{~S}$ to $21 \mathrm{~S}$ with points collected every 0.5 degree. The total magnetic field data and the magnetic declination were collected on the site NOAA (National Oceanic and Atmospheric Administration)

https://www.ngdc.noaa.gov/geomag/calculators/magcalc.shtml?useFullSite=true.

A minimum curvature technique was used with aninterpolation cell of 0.125 degrees. With this, six images of magnetic decline were constructed, as well as six images of total magnetic field for the years 1590, 1619, 1719, 1819, 1919 and 2019 as can be seen in Figure 5 to Figure 16.

The magnetic declination presents the measure of the angle formed between the direction of magnetic north pointed by the needle of a compass and the direction of geographic north. A positive magnetic declination means that magnetic north is shifted in clockwise (to the east), on the other hand, a negative magnetic declination means to say that it is counterclockwise (to the west).

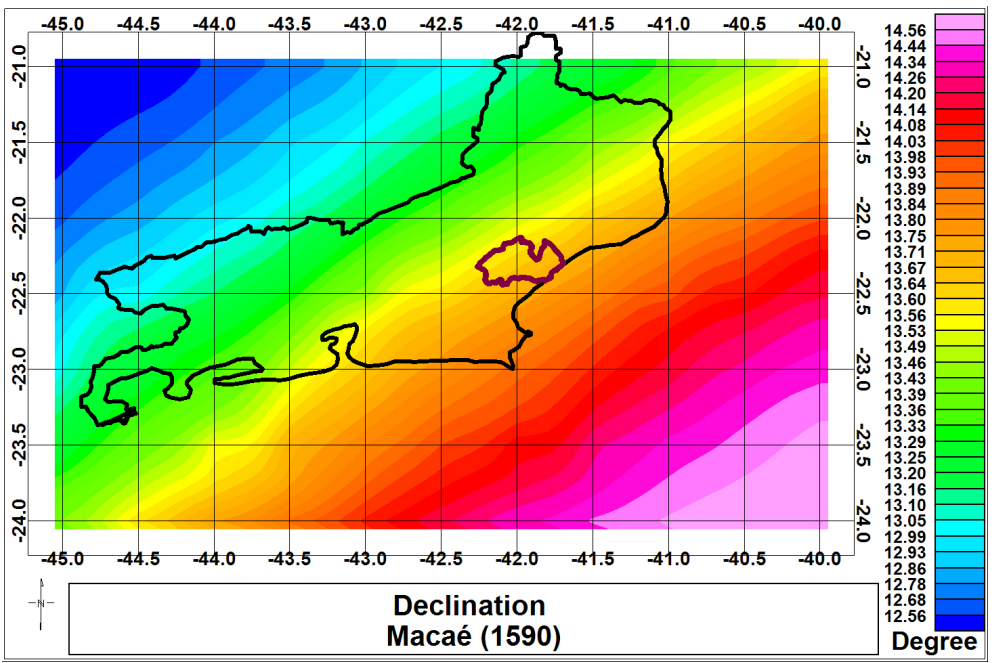

Figure 5. Magnetic Declination of the Macaé Region (1590).

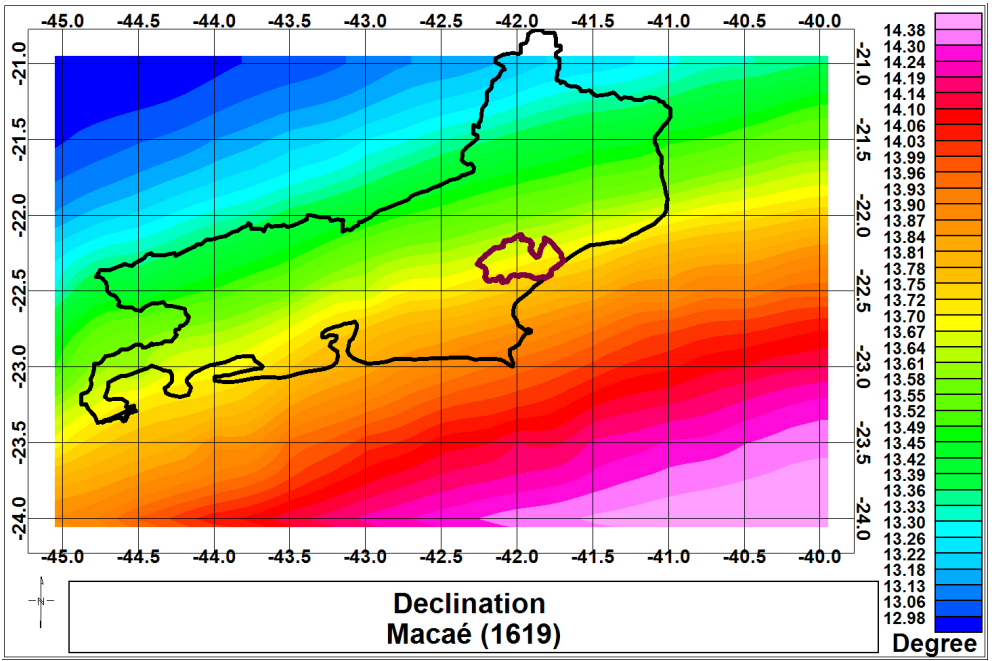

Figure 6. Magnetic Declination of the Macaé Region (1619). 


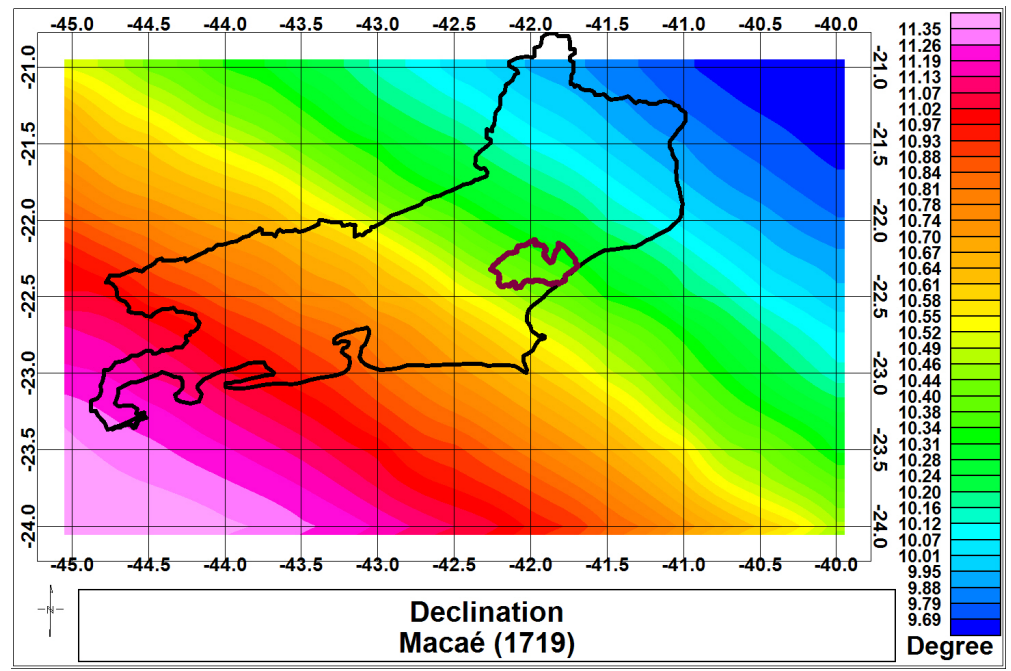

Figure 7. Magnetic Declination of the Macaé Region (1719).

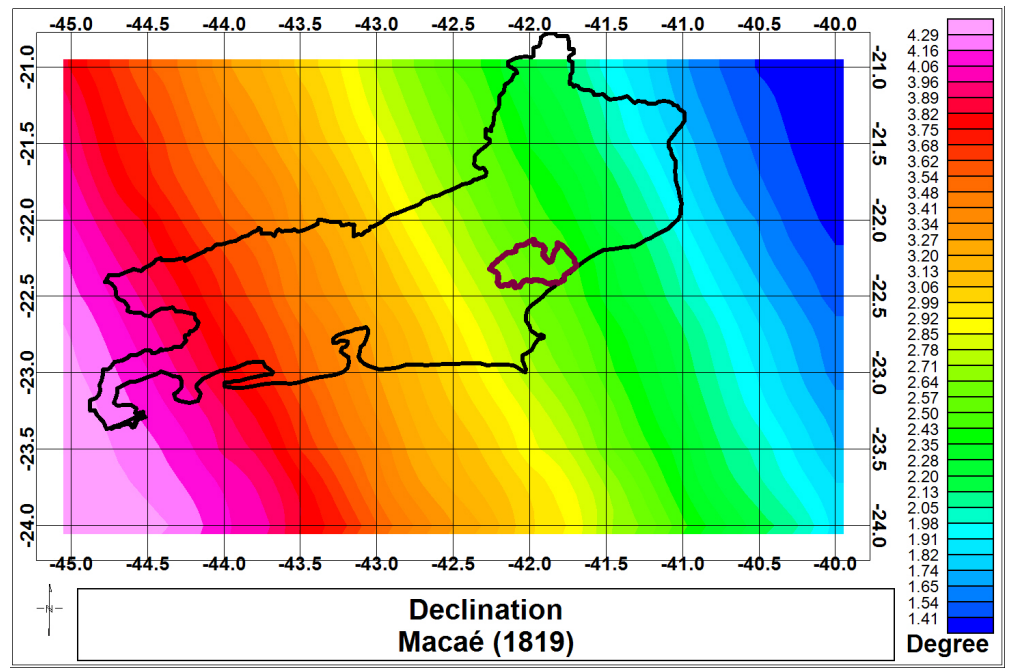

Figure 8. Magnetic Declination of the Macaé Region (1819).

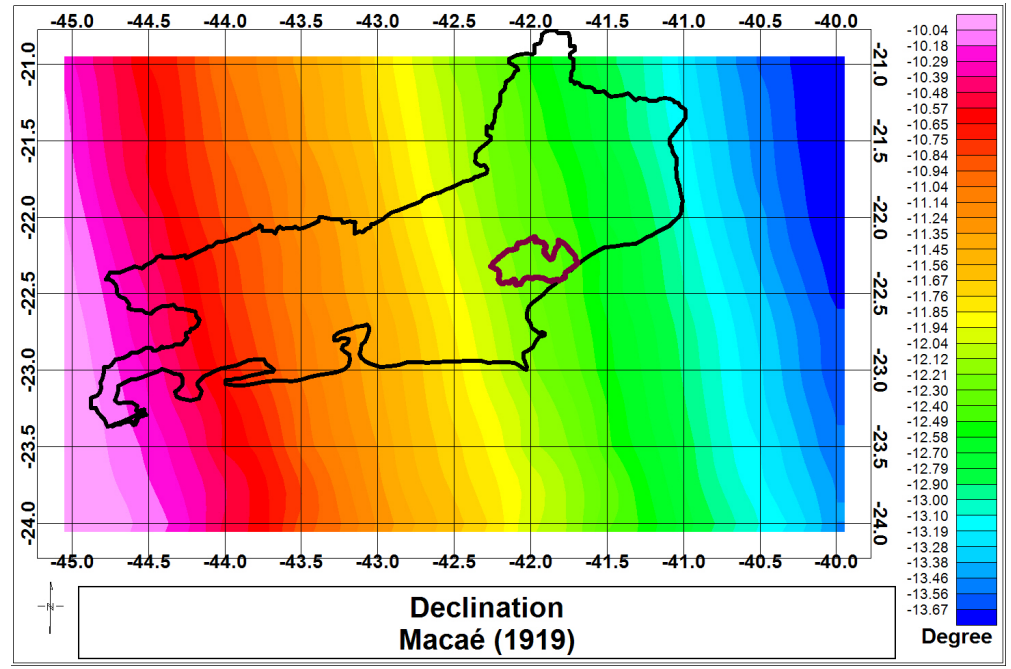

Figure 9. Magnetic Declination of the Macaé Region (1919). 


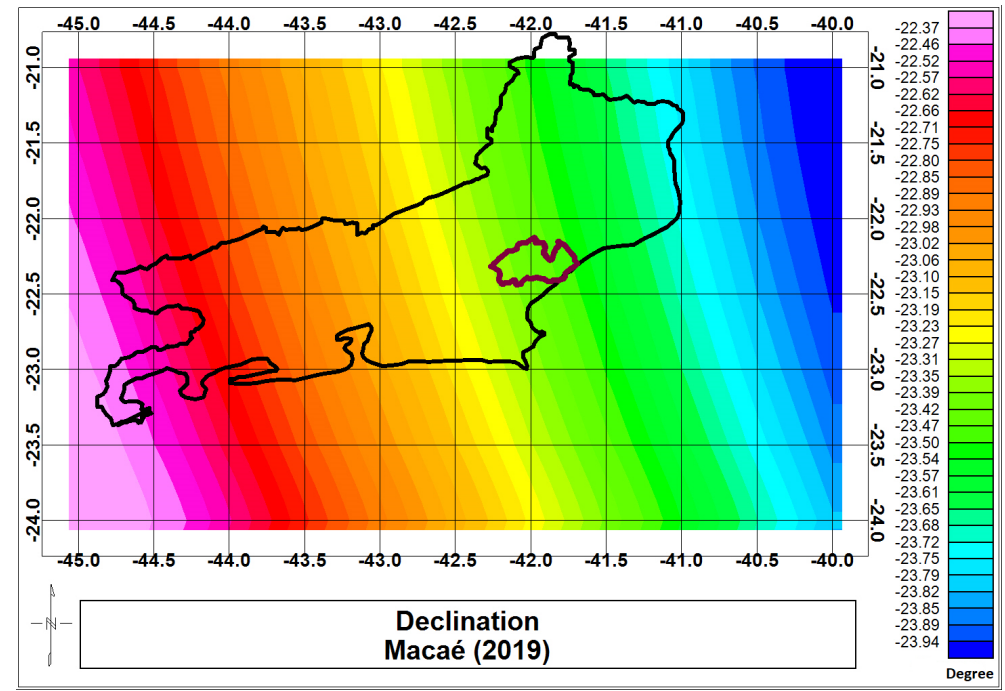

Figure 10. Magnetic Declination of the Macaé Region (2019).

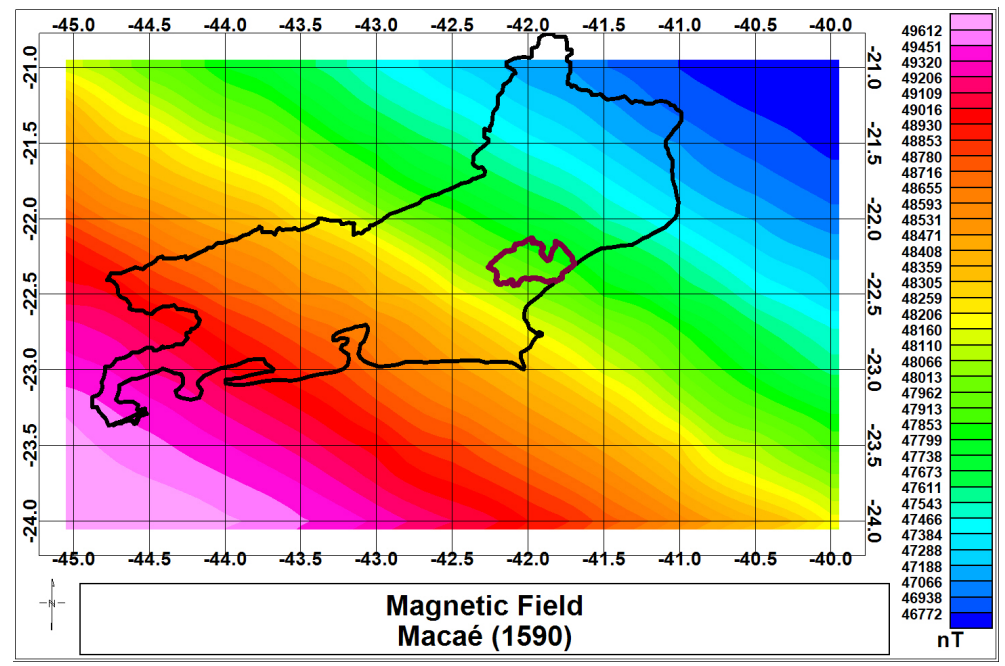

Figure 11. Total Magnetic Field of the Macaé Region (1590).

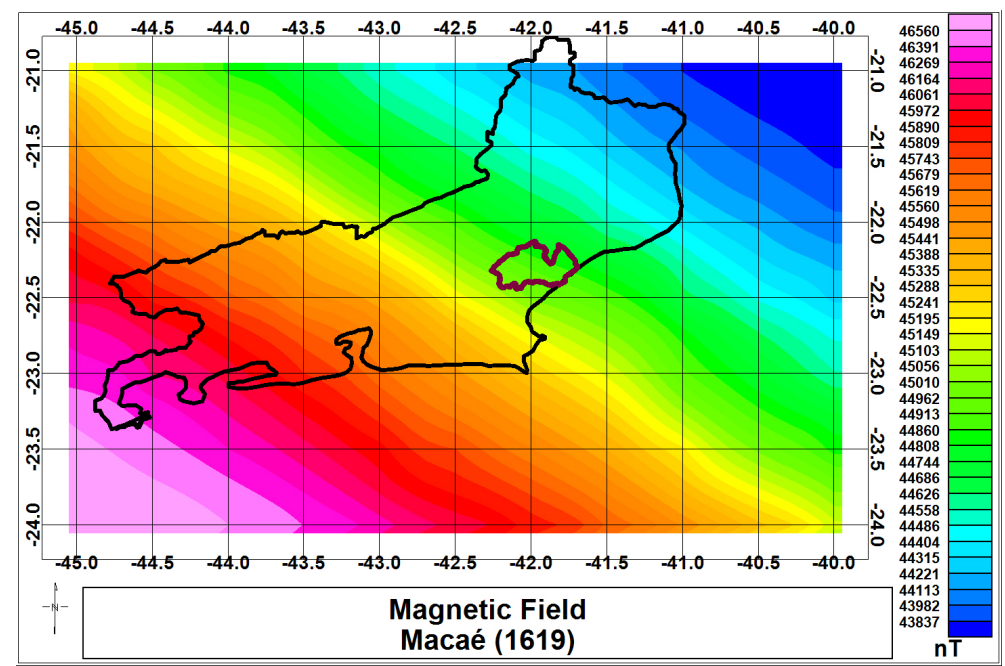

Figure 12. Total Magnetic Field of the Macaé Region (1619). 


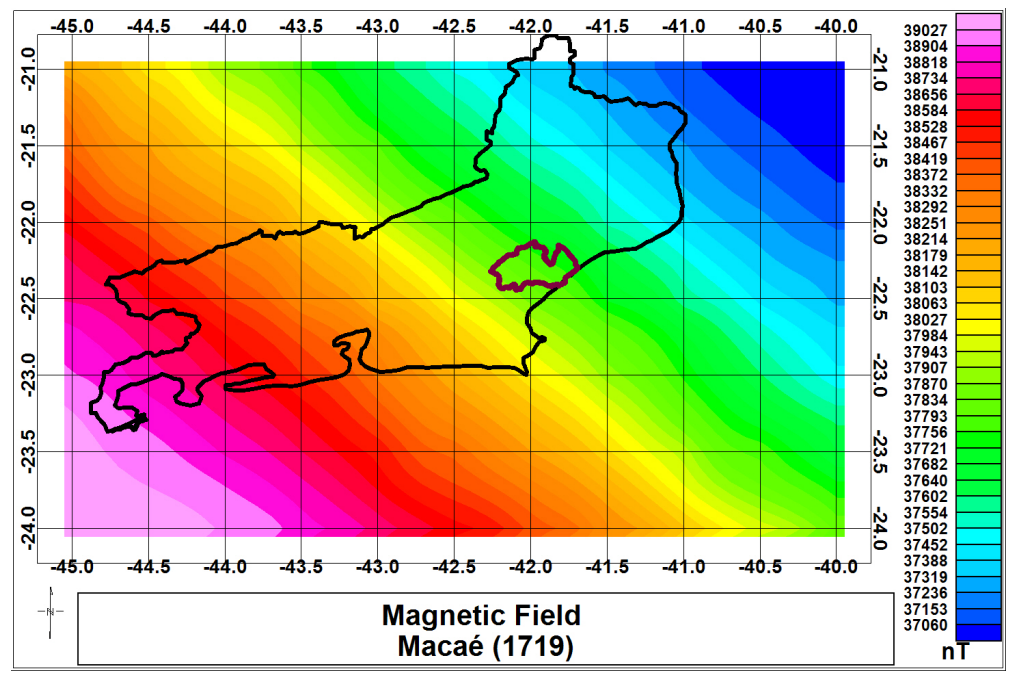

Figure 13. Total Magnetic Field of the Macaé Region (1719).

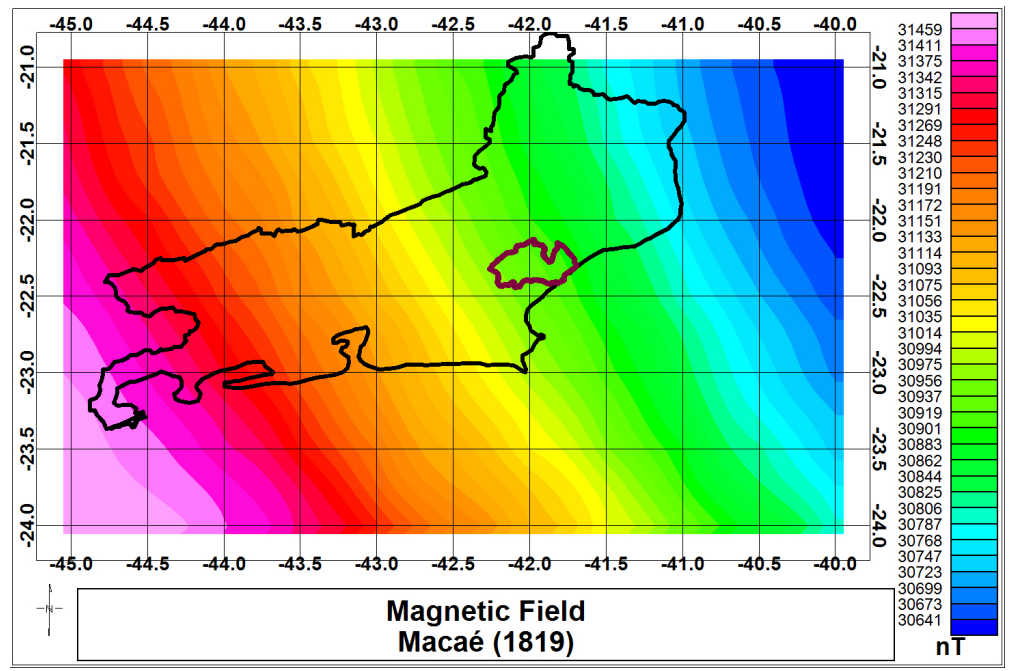

Figure 14. Total Magnetic Field of the Macaé Region (1819).

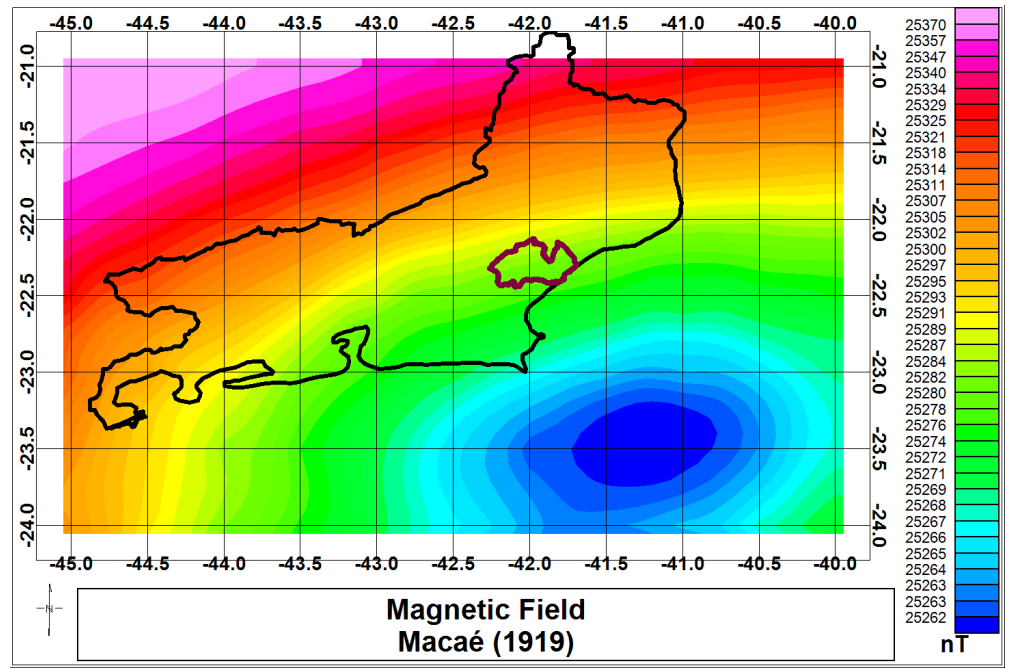

Figure 15. Total Magnetic Field of the Macaé Region (1919). 


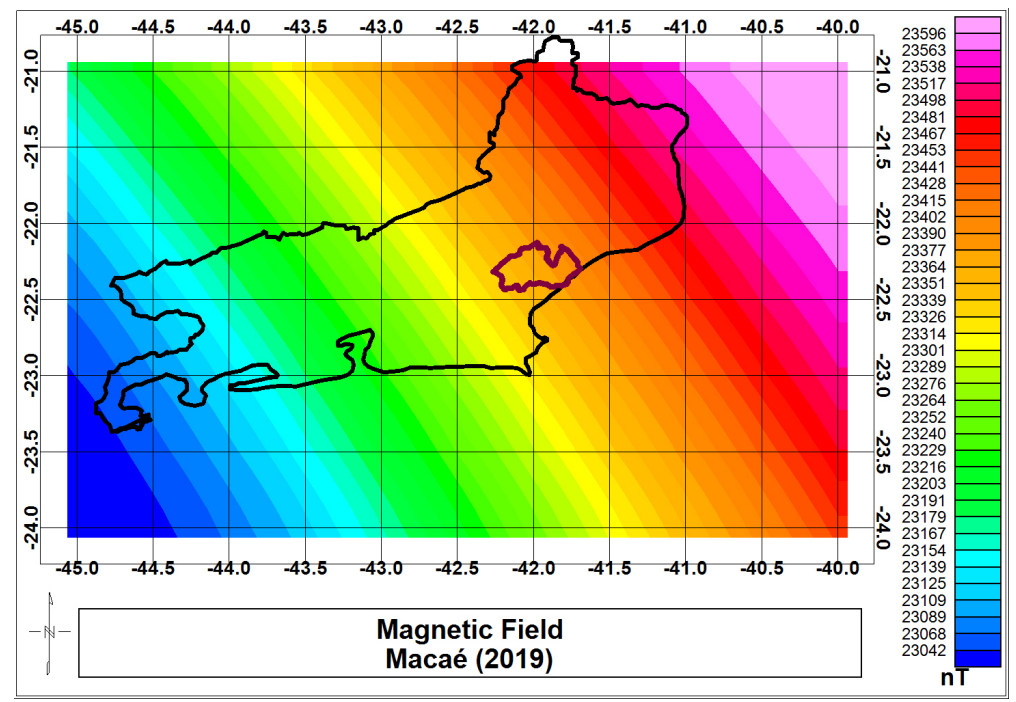

Figure 16. Total Magnetic Field of the Macaé Region (2019).

The analysis of the magnetic declination maps presents that, in 1590, the magnetic declination was clockwise at 13.7 degrees in the city of Macaé. This value decreased over time, reaching 2.7 degrees in 1819, and then showing a negative value (counterclockwise) around -23.4 degrees.

In addition, a change in the trend of increasing of magnetic declination can be observed, which in the maps from 1590 and 1619 occurred from northwest to southeast, and then from 1719 to 2019 with the trend changed from northeast to southwest.

As for the annual variations in magnetic declination, it can be seen that the lowest average variation in 100 years occurred between the years 1619 and 1719 with an average value around 0.003 degrees/year, whereas the largest variation occurred between the years 1819 and 1919 with about 0.143 degree/year.

Analyzing the total magnetic field maps, we can notice a great decrease in the magnetic field, which was around 48,000 $\mathrm{nT}$ in 1590, and it is around 23,000 $\mathrm{nT}$ currently. In this context, it is noticed the approximation of the SAMA towards the east with the magnetic field decreasing in all the time intervals considered. The highest average variation occurred between the years 1719 and 1819 with an annual average of $75.68 \mathrm{nT} /$ year, and the lowest variation occurred between the years 1919 and 2019 with an annual average of $17.74 \mathrm{nT} /$ year, which reveals the deceleration of the effects of the SAMA in the Macaé Region, still based on the fact that on the map of 2019 at any latitude, each point to the east has a greater magnetic field than to the west, that is, in the opposite direction to the Magnetic Anomaly.

\section{Conclusions}

In this paper, the temporal variations of the geomagnetic field and its effects in the Municipality of Macaé-Brazil were analyzed using historical data of the total magnetic field and magnetic declination from the IGRF model for more current 
data and the Gufm1 model for older data.

Through the analysis of the maps, a large variation of magnetic declination was observed, which in 1590 was 13.7 clockwise (west) to 23.7 counterclockwise (east) in the year 2019. Thus, in the period considered, there was an approximate variation of 37 degrees in the magnetic declination of the municipality of Macaé.

The maps also presented an approximation from east to west of the South Atlantic Magnetic Anomaly that was perceived through the weakening of the total magnetic field in the studied region, that was about $48,000 \mathrm{nT}$ in 1590 , reaching around 23,000 $\mathrm{nT}$ in 2019.

Thus, the present paper had as main importance the temporal study of the magnetic field behavior of the Earth and the South Atlantic Magnetic Anomaly, both being phenomena whose study is in state of art. Finally, in future works, it is suggested the temporal study of the geomagnetic field in the quadrant $60 \mathrm{~W}$ to $60 \mathrm{~L}$ of longitude and $40 \mathrm{~S}$ to $40 \mathrm{~N}$ of latitude, since this would allow visualizing the advance from east to west of the South Atlantic Magnetic Anomaly over time.

\section{Conflicts of Interest}

The authors declare no conflicts of interest regarding the publication of this paper.

\section{References}

[1] Laranja, S.R. (2018) Geomagnetic Study of the South Atlantic Magnetic Anomaly Considering the Geology of Southern Brazil, Paraguay and Northern Argentina.

[2] Moro, J., Jaskulski, T., Muralikrishna, P., Nardin, C.M. and Schuch, N.J. (2007) Estudos Do Plasma Ionosférico Na Região Da Anomalia Geomagnética Do Atlântico Sul. Relatório Final De Projeto De Iniciação Científica PIBIC/INPE CNPQ/MCT.

[3] Barraclough, D.R. (1974) Spherical Harmonic Analysis of the Geomagnetic Field for Eight Epochs between 1600 and 1910. Geophysical Journal of the Royal Astronomical Society, 36, 497-513. https://doi.org/10.1111/j.1365-246X.1974.tb00611.x

[4] Jackson, A., Jonkers, A.R.T. and Walker, M.R. (2000) Four Centuries of Geomagnetic Secular Variation from Historical Records. Philosophical Transactions of the Royal Society A: Mathematical, Physical and Engineering Sciences, 358, 957-990. https://doi.org/10.1098/rsta.2000.0569

[5] Alken, P., Erwan, T., Beggan, C., Aubert, J., Baerenzung, J., Brown, W., Califf, S., Chulliat, A., Cox, G.A., Finlay, C., Fournier, A., Gillet, N., Hammer, M., Holschneider, M., Hulot, G., Korte, M., Lesur, V., Livermore, P., Lowes, F. and Wardinski, I. (2020) Evaluation of Candidate Models for the 13th Generation International Geomagnetic Reference Field. 30 p.

[6] Hartmann, G.A. (2010) Archaeomagnetism in Brazil: Variations in the Intensity of the Terrestrial Magnetic Field in the Last Five Centuries. University of São Paulo, Institute of Astronomy, Geophysics and Atmospheric Sciences, São Paulo.

[7] LANDSAT. Earth Science Division and ECF Information. (ESDECFI). http://www.espo.nasa.gov/project/satellite.html 
[8] Lucchesi, C.F. (1998) Petróleo. Estudos Avançados, 12, 23 p. https://doi.org/10.1590/S0103-40141998000200003

[9] IBGE Instituto Brasileiro de Geografia e Estatística (2000) O Brasil Município por Município.

[10] Hartmann, G.A. (2005) A Anomalia Magnética do Atlântico Sul: Causas e Efeitos. Revista Brasileira de Geofísica, 24, 153 p. https://doi.org/10.1590/S0102-261X2006000300014

[11] Menezes, I.R.S., Figueiredo, J.M., Velloso, D.A.F., da Silva Bento, M.E., de Azevedo Lima, I. and Santos, H.S. (2019) Geomagnetic Mapping of the Macaé Region, Brazil. Open Access Library Journal, 6, e5593.

[12] Saboia, A.M. and Marques, G.C. (2020) South Atlantic Magnetic Anomaly (AMAS). Universidade Brasília, Instituto de Geociências.

[13] Almeida, P.D.S.C. (2007) Evolução do Mapa Dip Simulado pelo Modelo IGRF para a Localidade e São Luís (MA). Instituto Nacional de Pesquisas Espaciais.

[14] Gubbins, D. and Herrero-Bervera, E. (2007) Encyclopedia of Geomagnetism and Paleomagnetism. Springer, Berlin, Heidelberg.

https://doi.org/10.1007/978-1-4020-4423-6

[15] Thébault, E., et al. (2015) International Geomagnetic Reference Field: The 12th Generation. Earth, Planets and Space, 67, 79.

https://doi.org/10.1186/s40623-015-0313-0

[16] Jonkers, A.R.T., Jackson, A. and Murray, A. (2003) Four Centuries of Geomagnetic Data from Historical Cords. Reviews of Geophysics, 41, 1006.

https://doi.org/10.1029/2002RG000115 